\title{
Re-recognizing bromhexine hydrochloride: pharmaceutical properties and its possible role in treating pediatric COVID-19
}

\author{
Qibo $\mathrm{Fu}^{1} \cdot$ Xiao Zheng $^{2} \cdot$ Yunlian $\mathrm{Zhou}^{3} \cdot$ Lanfang Tang ${ }^{3} \cdot$ Zhimin Chen $^{3} \cdot$ Shaoqing $\mathrm{Ni}^{4}$ (I)
}

Received: 12 May 2020 / Accepted: 23 July 2020 / Published online: 1 September 2020

(C) Springer-Verlag GmbH Germany, part of Springer Nature 2020

The outbreak of coronavirus disease 2019 (COVID-19) caused by SARS-coronavirus 2 (SARS-CoV-2) has become a pandemic and constitutes a global health emergency [1]. The number of infected children is increasing, with reports of children's deaths [2-6]. As with adults, no effective anti-COVID19 therapy has been found yet for children [7-10].

Researchers from Germany recently provided evidence that the transmembrane protease serine 2 (TMPRSS2) plays a key role in SARS-CoV-2 binding to the host cell receptor, thereby achieving viral invasion and infection [11]. Other studies also suggest that TMPRSS2 is a drug target for treating COVID-19, and bromhexine was found to be a strong inhibitor of TMPRSS2 [12-14]. Bromhexine hydrochloride is approved in many countries as a commonly used over-thecounter (OTC) expectorant for both adults and children and has been marketed since $1963[15,16]$. It is characterized by low side effects and relatively low cost [17]. Considering all these characteristics, bromhexine hydrochloride could be an ideal candidate as a potential COVID-19 treatment [17-19].

As far as safety is concerned, the incidence of adverse reactions to bromhexine hydrochloride has been similar in children and adults. Though unlikely, if there are signs or

Zhimin Chen

zmchen@zju.edu.cn

Shaoqing $\mathrm{Ni}$

chgcp@zju.edu.cn

1 National Clinical Research Center for Child Health, National Children's Regional Medical Center, Children's Hospital, Zhejiang University School of Medicine, Hangzhou 310052, China

2 State Key Laboratory of Natural Medicines, College of Pharmacy, China Pharmaceutical University, Nanjing 210009, China

3 Pulmonary Department, Children's Hospital, Zhejiang University School of Medicine, Hangzhou 310052, China

4 National Clinical Trial Institute, National Clinical Research Center for Child Health, National Children's Regional Medical Center, Children's Hospital, Zhejiang University School of Medicine, Hangzhou 310052, China symptoms of skin reactions or allergic reactions, patients should seek medical advice and discontinue bromhexine hydrochloride immediately [15]. It should be used with caution in the presence of obstructed bronchial motor function or large amounts of secretions [15]. Also, it is not recommended for use in children under 2 years of age owing to the risk of lifethreatening side effects [20].

According to the results of cell experiments, the half maximal inhibitory concentration $\left(\mathrm{IC}_{50}\right)$ of bromhexine hydrochloride on TMPRSS2 protease is $0.75 \mu \mathrm{M}$, and the target cell concentration is about $308.62 \mathrm{ng} / \mathrm{mL}$ [14]. The pharmacokinetic data for oral bromhexine hydrochloride show that the adult maximum blood concentration $\left(\mathrm{C}_{\max }\right)$ with oral administration of $8 \mathrm{mg}$ bromhexine hydrochloride is $22.50 \pm 7.50 \mu \mathrm{g} / \mathrm{L}$ [21], and the concentration in the parenchymal tissue of the lung is 54 $132.75 \mathrm{ng} / \mathrm{mL}$, far less than the concentration of target cells [22]. Because the new pharmacokinetic parameters of bromhexine hydrochloride are proportional to an oral dose of $8-32 \mathrm{mg}$ [21], the pulmonary concentration with $32 \mathrm{mg}$ of the drug would be $216-531 \mathrm{ng} / \mathrm{mL}$ (median $373.5 \mathrm{ng} / \mathrm{mL}$ ), which could achieve the target cell concentration to inhibit TMPRSS2. In adults, Yong et al. suggested an oral dose of bromhexine hydrochloride up to $96 \mathrm{mg}$ per day in clinical practice [23] to maximize the drug concentration in blood. We did not find reports of pediatric use experiences [24].

As of June 12, 2020, six clinical trials have been registered to explore the therapeutic potential of oral bromhexine hydrochloride in patients with COVID-19. The only clinical trial in children was registered by our group [25]. The use of new therapeutic methods in children should be undertaken very cautiously, because the pathogenesis of COVID-19 in children is still not clear. After comprehensive consideration of age, pharmacokinetics and safety, we propose initially studying the use of bromhexine hydrochloride at the maximum dosage recommended by drug labels in pediatric patients with suspected and mild cases of COVID-19. The oral dose will depend on age as follows: $12 \mathrm{mg}, 24 \mathrm{mg}$ and $48 \mathrm{mg}$ daily in three divided doses for ages $2-5$ (weight $<50 \mathrm{~kg}$ ), 6-13 
(weight $\geq 50 \mathrm{~kg}$ ) and 14-18, respectively. However, we have not recruited patients because very few children have been diagnosed with COVID-19 in China thus far.

We propose that the use of bromhexine hydrochloride in the treatment of pediatric COVID-19 be studied in clinical research and clinical practice to fight against the spread of COVID-19 throughout the world.

Acknowledgements We would like to thank Prof. Hao Haiping for all his help with the guidance and article modifications.

Code availability Not applicable.

Authors' contributions All authors contributed to the initial discussion. FQB, ZX and NSQ wrote the first draft. All authors contributed papers and guidance to initial submission. After review and request for more information, FQB and NSQ updated the document; all authors made final recommendations and edits. All authors approved the final version of the manuscript.

Funding This work was supported financially by the National Natural Science Foundation of China (No. 81573516).

Availability of data and material All data generated or analyzed during this study are included in this letter.

\section{Compliance with ethical standards}

Conflict of interest/competing interests The authors have no conflicts of interest to disclose.

Ethical approval Not applicable.

Consent to participate Not applicable.

Consent for publication Informed consent for publication was obtained from all participants.

\section{References}

1. World Health Organization (2020) Coronavirus disease (COVID19) outbreak situation Report - 145. https:/www.who.int/docs/ default-source/coronaviruse/situation-reports/20200613-covid-19sitrep-145.pdf?sfvrsn=bb7c1dc9 2. Accessed 14 June 2020

2. Shen K, Yang Y (2020) Diagnosis and treatment of 2019 novel coronavirus infection in children: a pressing issue. World $\mathrm{J}$ Pediatr 16:219-221. https://doi.org/10.1007/s12519-020-00344-6

3. Feng K, Yun Y, Wang X, Yang G, Zheng Y, Lin C, Wang L (2020) Analysis of CT features of 15 children with 2019 novel coronavirus infection. Zhonghua Er Ke Za Zhi 58:275-278. https://doi.org/10. 3760/cma.j.cn112140-20200210-00071 (in Chinese)

4. Cai J, Wang X, Ge Y et al (2020) First case of 2019 novel coronavirus infection in children in Shanghai. Zhonghua Er Ke Za Zhi 58: 86-87. https://doi.org/10.3760/cma.j.issn.0578-1310.2020.02.002 (in Chinese)

5. Zhang Y, Lin D, Xiao M et al (2020) 2019-novel coronavirus infection in a three-month-old baby. Zhonghua Er Ke Za Zhi 58: E006. Advance online publication. https://doi.org/10.3760/cma.j. issn.0578-1310.2020.0006 (in Chinese)
6. Zeng L, Tao X, Yuan W et al (2020) First case of neonate infected with novel coronavirus pneumonia in China. Zhonghua $\mathrm{Er} \mathrm{Ke} \mathrm{Za}$ Zhi 58:E009. Advance online publication. https://doi.org/10.3760/ cma.j.issn.0578-1310.2020.0009 (in Chinese)

7. Chen Z, Fu J, Shu Q (2020) New coronavirus: new challenges for pediatricians. World J Pediatr 16:222. https://doi.org/10.1007/ s12519-020-00346-4

8. Shen K, Yang Y, Wang T et al (2020) Diagnosis, treatment, and prevention of 2019 novel coronavirus infection in children: experts' consensus statement. World J Pediatr 16:223-231. https://doi.org/ 10.1007/s12519-020-00343-7

9. Pediatric Branch of Hubei Medical Association, Pediatric Branch of Wuhan Medical Association, Pediatric Medical Quality Control Center of Hubei (2020) Zhongguo Dang Dai Er Ke Za Zhi 22: 96-99 (in Chinese)

10. Chen Z, Fu J, Shu Q et al (2020) Diagnosis and treatment recommendations for pediatric respiratory infection caused by the 2019 novel coronavirus. World J Pediatr 16:240-246. https://doi.org/10. 1007/s12519-020-00345-5

11. Hoffmann M, Kleine-Weber H, Schroeder S et al (2020) SARSCoV-2 cell entry depends on ACE2 and TMPRSS2 and is blocked by a clinically proven protease inhibitor. Cell 181:271-280.e8. https://doi.org/10.1016/j.cell.2020.02.052

12. Laporte M, Naesens L (2017) Airway proteases: an emerging drug target for influenza and other respiratory virus infections. Curr Opin Virol 24:16-24. https://doi.org/10.1016/j.coviro.2017.03.018

13. Shen $\mathrm{L}, \mathrm{Mao} \mathrm{H}, \mathrm{Wu} \mathrm{Y}$ et al TMPRSS2: a potential target for treatment of influenza virus and coronavirus infections. Biochimie 142: 1-10. https://doi.org/10.1016/j.biochi.2017.07.016

14. Lucas JM, Heinlein C, Kim T et al (2014) The androgen-regulated protease TMPRSS2 activates a proteolytic cascade involving components of the tumor microenvironment and promotes prostate cancer metastasis. Cancer Discov 4:1310-1325. https://doi.org/10. 1158/2159-8290.CD-13-1010

15. European Medicines Agency. Ambroxol and bromhexine Article 31 Referral- PRAC assessment report. https://www.ema.europa.eu/ en/documents/referral/ambroxol-bromhexine-article-31-referralprac-assessment-report_en.pdf. Accessed 25 March 2020

16. Chang C, Cheng A, Chang A (2014) Over-the-counter (OTC) medications to reduce cough as an adjunct to antibiotics for acute pneumonia in children and adults. Cochrane Database Syst Rev 3: CD006088. https://doi.org/10.1002/14651858.CD006088.pub4

17. Depfenhart M, de Villiers D, Lemperle G, Meyer M, Di Somma S (2020) Potential new treatment strategies for COVID-19: is there a role for bromhexine as add-on therapy? [published online ahead of print, 2020 May 26]. Intern Emerg Med 1-12. doi:https://doi.org/ $10.1007 / \mathrm{s} 11739-020-02383-3$

18. Maggio R, Corsini G (2020) Repurposing the mucolytic cough suppressant and TMPRSS2 protease inhibitor bromhexine for the prevention and management of SARS-CoV-2 infection. Pharmacol Res 157:104837. https://doi.org/10.1016/j.phrs.2020.104837

19. Habtemariam S, Nabavi S, Ghavami S, Cismaru C, BerindanNeagoe I, Nabavi S (2020) Possible use of the mucolytic drug, bromhexine hydrochloride, as a prophylactic agent against SARSCoV-2 infection based on its action on the transmembrane serine protease 2. Pharmacol Res 157:104853. https://doi.org/10.1016/j. phrs.2020.104853

20. Rimsza M, Newberry S (2008) Unexpected infant deaths associated with use of cough and cold medications. Pediatrics 122:e318-e322. https://doi.org/10.1542/peds.2007-3813

21. Yang L, Yuan Y, Tu X (2000) Determination of Bromhexine in plasma by gas chromatography-electron capture detection and pharmacokinetic studies. Se Pu 18:543-545 (in Chinese)

22. Zhang W, Feng F, Wang Y (2008) HPLC-MS assay for the determination of bromhexine in human plasma and application to 
bioequivalence studies. Yao Xue Yu Lin Chuang Yan Jiu 16:114117 (in Chinese)

23. Yang Y, Shen H (2020) Potential mechanistic investigation of Bromhexine for the treatment of COVID-19. Zhongguo Zhong Yao Za Zhi 55:679-684 (in Chinese)

24. Lu X, Zhang L, Du H, Zhang J et al (2020) SARS-CoV-2 infection in children. N Engl J Med 382:1663-1665. https://doi.org/10.1056/ NEJMc2005073
25. Chinese Clinical Trial Registry (2020) Evaluating the Efficacy and Safety of Bromhexine Hydrochloride Tablets in Treating Pediatric novel coronavirus pneumonia (COVID-19). http://www.chictr.org. $\mathrm{cn} /$ showprojen. aspx $?$ proj=55097. Accessed 13 June 2020. (in Chinese)

Publisher's note Springer Nature remains neutral with regard to jurisdictional claims in published maps and institutional affiliations. 